Eeatures characteristic of Mongolian skulls, the facial bones being more European in type, and the nasi-malar angle only $129 \mathrm{deg}$. The affinities of the Ainos are at present a matter for speculation.

\section{The Eskimo}

The original inhabitants of the whole of the New World are light brown, or copper-coloured, have straight black hair, and show, amid considerable diversity in detail in particular regions, a far greater resemblance than can be found in any other portion of the world's surface of equal extent. The Eskimo, inhabiting the most northern portion of the continent, stand, in many respects, apart from the others, and are evidently quite as nearly allied to some of the Asiatic races as they are to the Americans. These people call themselves Inmuit, which signifies nothing more than "the men," or "the people." The word Esquimaux, as it is rendered in French, or Eskimo, in the Danish method of spelling, now usually adopted in this country, was applied to them by a neighbouring tribe of Indians, and is said to mean "eaters of raw flesh." They dwell in various scattered localities near the northern coast of North America and the great adjacent islands, from Behring's Straits to Greenland, and on the north coast of Labrador. Like the MongoloAltaic races of Asia, they lead a nomadic life, modified somewhat by the peculiarities of the surrounding physical conditions, dwelling in tents in summer, and in houses of snow in winter. Agriculture being impossible in such a climate, their only means of subsistence is hunting and fishing. The flesh of seals, cetaceans, and reindeer forms their principal food. In the pursuit of the two former by sea they use boats, which they manage with great dexterity. They train dogs to draw their sledges, but, unlike the Laplanders, do not domesticate the reindeer. They clothe themselves comfortably in dresses of skin, and employ bows, arrows, and harpoons in the chase. In Greenland they have reached a considerable degree of civilisation, but even here, as elsewhere, their numbers seem to be diminishing.

The Eskimo are generally below the middle size; their head is large, their legs short, and their hands and feet small; their complexion is dusky or swarthy. Their hair is black, straight, and coarse, the beard and moustache generally scanty, though sometimes moderately developed. The eyes are small, black, and sparkling; the elevation of the outer end of the aperture and the vertical fold covering the inner canthus, spoken of before as characteristic of the most typical Mongolian races, have often been observed in them. The nose is usually straight and narrow, and more or less sunken between the prominent cheeks. The mouth is large and the lips rather prominent, generally kept somewhat apart. The chin is small and pointed.

The College Museum contains as many as twenty-seven adult skulls of Eskimos, twenty-four of which are in a condition to form reliable measurements. Of these seventeen appear to be those of males and seven of females.

A typical Eskimo skull always presents such marked characters that it can never be mistaken for that of any other of the groups of mankind. It is of very large size, especially in relation to the rather small stature of the people, the average capacity of 17 male crania in the collection being 1,546 c.c. or $94 \% 3$ c. inches. This is almost exactly the same as the average English (of the lowest class), but it exceeds that of 74 modern Italian males by 7 I C.c., and it is above the average of Australian males by as much as $26 \mathrm{r}$ c.c. or 16 c. inches. The large size of the brain of all hyperborean races, Lapps as well as Eskimo, seems not necessarily to be connected with intellectual development, but may have some other explanation not at present quite apparent. The next distinctive character of the Eskimo skull is its great length and narrowness, especially in the upper part. The base is fairly broad, and the mastoid processes are well developed; but, instead of expanding upwards to the parietal region, it narrows, and, towards the median line above, contracts so rapidly that the upper part of the skull has the form of the roof of a house. Measurements of various series of Eskimo skulls give remarkably uniform results as regards the latitudinal index, the average being from $7 \times 2$ to $71 \% 4$, so that it may be considered as perfectly established, that the Eskimo are among the most dolichocephalic of races. The female skulls are somewhat broader than the male. The index of height is somewhat greater than that of breadth, averaging $73 \cdot 5$. The cranial sutures are very simple; and among the specimens examined there is no case of metopism or persistence of the frontal suture, nor is there any case of the squamosal bone meeting the frontal at the pterion.

The whole face is large, both high and broad; the forehead is flat, the glabella little developed; the orbits are round, and the malar bones of great size and very prominent, giving a nasi-malar angle of $144 \mathrm{deg}$. The nasal bones are small and narrow, often coming to a point at their upper ends, and the whole aperture is very long and narrow. The Eskimo are, in fact, the most leptorhine of all races; the average nasal index of the 17 male skulls before spoken of, being only $42^{\prime} 2$, the average of European crania being about 47 , and that of Australians 56. The projection of the jaw is moderate, giving an alveolar index of 100.8 , which brings them into the mesognathous category, with an inclination towards prognathism. The arch formed by the series of teeth is remarkably short, broad, and round. The teeth are small, and generally become worn down to stumps as life advances.

Two out of the three Eskimo skeletons in the Museum possess one more than the usual number of vertebræ, the additional one being interposed between the dorsal and lumbar series, and partaking of the character of both. The brim of the pelvis is remarkably wide transversely, and thus, as also in the limbs, they deviate widely from the negro type : for example, the humero-radial index, which in the Andamanese is as high as 82, in Negroes 79, in Australians 77, and in Europeans 74, does not exceed $7 \mathrm{I}^{\circ} 3$ in either of the three skeletons, the average being $7 \mathrm{I} \cdot \mathrm{I}$.

Dr. Barnard Davis has shown that the special peculiarities of the Eskimo skull are most marked in Greenland; there is also good evidence that the Eskimo have migrated from the west towards the east, and did not reach Greenland, at all events in its southern parts, until the fourteenth century. Their affinities, moreover, as shown by physical characters, are more with the inhabitants of North-Eastern Asia than with the American Indians, and it is not at all improbable that they are derived from the same stock as the Japanese. In this case the peculiarities by which the Eskimo are differentiated from the Asiatic Mongolians cannot have been developed by crossing with other nations, on account of their complete isolation, but must be attributed to those gradual modifications, produced by causes at present little understood, by which most of the striking variations we have met with in the human species have been brought about; modifications more strongly expressed the more completely isolated the race has become, and the further removed from its original centre of distribution.

\section{OUR ASTRONOMICAL COLUMN}

The Dunsink OBSERVAToRy, Dublin.-The third part of "Astronomical Observations and Researches made at Dunsink, the Observatory of Trinity College, Dublin," has been published by Dr. Ball. It contains four papers, the first by the previous director, Dr. Brunnow, presenting a discussion of observations of the 
planetary nebula H. IV. 37 , the position of which is in R.A. 17h. $58 \mathrm{~m}$. 36s., N.P.D. $23^{\circ} 21^{\prime} \cdot 8$ for 1880 . The nebula appears in the South-refractor as a somewhat elliptical disk, whose major axis is about half a minute, and has in the centre a well-defined point resembling a star of the eleventh magnitude. This point was compared in declination with a star to the north of the tenth magnitude, preceding the nebula by $25 \mathrm{~s}$., the same method of observing being used that had been adopted in Dr. Brunnow's earlier researches on stellar parallax. The observations extend over thirty-three nights, from 187 , August 13 , to 1872 , August 6 , and their discussion gives for the parallax of the nebula, $+0^{\prime \prime} \cdot 047 \pm 0^{\prime \prime} \cdot 030$. Prof. Bredichin, in "Annales de l'Observatoire de Moscou," vol. iii., has found a negative parallax $\left(-0^{\prime \prime} \cdot 064 \pm 0^{\prime \prime} \cdot 039\right)$, using also the method of differences of declination with the same star of comparison. The results of these investigations may be taken to indicate that the parallax of this planetary nebula if measurable at all must be very small. The second paper contains Dr. Ball's observations of $6 \mathrm{r}$ Cygni, and his determination of its parallax therefrom. By what was at first an inadvertence, instead of using the following of the two components as Dr. Brunnow had done, the preceding one was observed, and the mistake not being remarked until the series was considerably advanced, it was resolved to complete it as begun; perhaps the result possesses for this reason additional interest. Dr. Ball finds for the parallax $+0^{\prime \prime} \cdot 4654 \pm 0^{\prime \prime} \cdot 0497$, which is about a mean of the values obtained by Bessel, Johnson, Peters, Struve, and Auwers, which appear entitled to the greatest weight. The observations extending from 1877 , July 3 , to 1878 , June $x$, are given in their original form. The third paper, aiso by Dr. Ball, relates to "observations in search of stars with a large annual parallax," forty-two stars being examined for this purpose, including several red and variable stars: the results, however, are found to be entirely negative as regards the object in view, no amount of parallax worth following up being suggested. The principle upon which the observations were made is fully described and their details appended to the memoir. The last portion of the Dunsink publication contains Dr. Brunnow's measures of double-stars $1870-73$.

THE SOLAR ECLIPSE OF JULY 19.-The Observatory of Paris is situate very close upon the northern line of simple contact in this eclipse, which will add interest to observations that may be made there. The Connaissance des Temps employing the lunar tables of Hansen and the solar tables of Leverrier, gives the magnitude of the eclipse only 0.013 (the sun's diameter being taken as unity), commencement at $7 \mathrm{~h} .46 \cdot \mathrm{mm}$. A.M. mean time at Paris, ending at $8 \mathrm{~h} .54 \mathrm{~m}$. At Gibraltar the magnitude of the eclipse will be 0.32 at $7 \mathrm{~h} .9 \mathrm{~m}$. local mean time, and at Malta $0^{\circ} 38$ at $8 \mathrm{~h} .46 \mathrm{~m}$. As we have before remarked the only civilised station where a great eclipse is likely to be witnessed is Aden. The eclipse is strictly an annular one, but the moon's augmented semi-diameter is only five seconds less than the sun's semi-diameter, where the greatest phase occurs near apparent noon. At Aden at Oh. I2m. P.M. 97-100ths of the sun's diameter will be covered by the moon; the line of annular eclipse falls upon the opposite African coast.

PERIODICAL COMETS IN I880.-Two known comets of short period will be observable before the end of the ensuing year, viz., Winnecke's, which may be in perihelion early in December, and Faye's, which, according to Dr. Axel-Möller, again arrives at its least distance from the sun in January, $188 \mathrm{r}$. The perturbations of Winnecke's comet during the actual revolution will not be important, and from Prof. Oppolzer's elements of 1875 it seems likely that difficulty may be experienced in securing observations, the track in the heavens if we assume the time of perihelion passage to be December $1 \cdot 5$ being as follows :--

\begin{tabular}{|c|c|c|c|c|c|c|c|c|c|c|}
\hline \multirow{2}{*}{\multicolumn{2}{|c|}{$\begin{array}{l}\text { 1880-I. } \\
\text { Oct. } 2\end{array}$}} & \multicolumn{4}{|c|}{ Right Ascension. } & \multicolumn{3}{|c|}{ Declination. } & \multicolumn{2}{|c|}{ Dist. from eart } \\
\hline & & ... & 196 & 29 & ... & $\cdots$ & -015 & $\ldots$ & $\cdots$ & $2 \cdot 223$ \\
\hline Nov. & I & $\ldots$ & 224 & 3 & ... & $\cdots$ & - II 35 & ... & $\ldots$ & $1 \cdot 944$ \\
\hline \multirow{5}{*}{ Jan. } & I I & $\ldots$ & 276 & 17 & ... & $\cdots$ & -2321 & ... & & I.753 \\
\hline & $2 I$ & $\cdots$ & 290 & 43 & $\cdots$ & $\cdots$ & -2340 & ... & $\ldots$ & I.767 \\
\hline & $3 \mathbf{I}$ & $\cdots$ & 304 & $3 I$ & ... & $\cdots$ & -2243 & ... & . & $1 \cdot 808$ \\
\hline & IO & $\cdots$ & 317 & $\mathrm{I}_{4}$ & ... & $\cdots$ & -2046 & .. & $\cdots$ & $x \cdot 876$ \\
\hline & 30 & $\cdots$ & $33^{8}$ & 44 & $\cdots$ & $\cdots$ & -15 I3 & $\cdots$ & $\ldots$ & $2 \cdot 072$ \\
\hline
\end{tabular}

\section{METEOROLOGICAL NOTES}

THE Eleventh Contribution to Meteorology by Prof. Loomis appears in the American Journal of Science and Arts for this month. With the view of inquiring whether areas of low atmospheric pressure sometimes result from a circulation of the surface winds not extending to a height of 6,000 feet, Prof. Loomis has examined eightynine storms and compared in each case the average direction and force of the surface winds near the base of Mount Washington with the winds at the top of the mountain. In the majority of those cases in which a storm with its area of low barometer passes over the New England States, the usual system of circulating winds which prevails at the surface, does not extend to the height of 6,000 feet. In cases, however, when the depression is unusually great, this system of circulating winds extends to that height. When the system of circulating winds reaches to the top of Mount Washington, the change of wind into the east usually begins near the base eleven hours sooner than on the top of the mountain; and the change subsequently into the west usually begins at the base five hours sooner than on the top.

IN the same paper Prof. Loomis examines eight storms, the average courses of which were approximately from south to north, and six storms which travelled from north to south, with the view of obtaining information from such abnormal storm paths, regarding the causes which determine the movement of storms with their low barometers from place to place. These two groups of storms present characteristics.very different from each other. - As contrasted with the other group, storms moving to northward show a central pressure, becoming more depressed as they advance; the southerly winds accompanying them are marked by a greater humidity and velocity; and the rainfall is very greatly in excess. If attention be exclusively directed to storms moving to northward the facts seem to favour the idea that in a great storm the condensation of vapour is an efficient cause which controls the movement of the winds. Storms moving to southward, however, show very different results; areas of low pressure being observed to be formed with little rain and sometimes even with none at all. The general conclusion the inquiry seems to point to is that the initial depression of the barometer is the result of a system of circulating winds, the most frequent cause of which is two or more areas of high pressure at considerable distances, ofter 1,400 miles from each other, differences of temperature and humidity being important agents in producing, but more especially in maintaining, such a system of winds. If this be so, then the points in the inquiry calling for the most serious attention are the causes which conspire in bringing about those wide areas of high pressure round a region of lower though still high pressure and the concentration of moister and warmer air over this region.

THE Results of the Meteorological and Magnetic Observations for 1878 made at Stonyhurst College have just appeared. To the routine work of the observatory has been added the preparation of an agricultural report sent weekly to the Meteorological Office; and to the usual observations are added observations of crops, flowers, shrubs, and trees, and a complete and very valuable table 